\title{
ROUSSEAU E O PARADOXO DA CENSURA
}

\author{
José Benedito de Almeida Júnior ${ }^{1}$ \\ Universidade Federal de Uberlândia (UFU) \\ (iD) https://orcid.org/0000-0001-5801-7284 \\ E-mail: jbeneditoalmeida@gmail.com \\ Loyana Christian de Lima Tomaz \\ Universidade Estadual de Minas Gerais (UEMG) \\ (D) https://orcid.org/0000-0002-3595-0570 \\ E-mail: loyancl@gmail.com \\ Luciana Xavier de Castro ${ }^{3}$ \\ Universidade Federal de Uberlândia (UFU) \\ (iD) https://orcid.org/0000-0001-5568-3660 \\ E-mail: luciana_filos@yahoo.com.br
}

\section{RESUMO:}

Este artigo tem por objetivo analisar a aparente contradição entre a instituição da censura no Contrato Social de Rousseau e a censura que sofreu em Genebra e Paris. Para tanto analisaremos o conceito de censura no Contrato Social e os argumentos utilizados por Rousseau nas obras Cartas escritas da Montanha e a Carta à Christophe Beaumont, com apoio na obra de alguns comentadores da obra política de Rousseau. Nossos estudos nos levam a concluir que Jean-Jacques Rousseau admite, de fato, a possibilidade da instituição da censura, no entanto, a ação dos censores deve ser restrita pela opinião pública, tal como a do príncipe em relação às leis. Além disso, se há um processo semelhante deveria atender todos os requisitos da legislação civil do Estado no qual ocorre. Tanto em Paris, como em Genebra Rousseau discorda do modo como procederam em relação às suas obras e sua pessoa.

PALAVRAS-CHAVE: Censura; Filosofia; Política; Religião; Rousseau.

\section{ROUSSEAU AND THE PARADOX OF CENSORSHIP}

\begin{abstract}
:
This article aims to analyze the apparent contradiction between the institution of censorship in the Social Contract of Rousseau and the censorship he suffered in Geneva and Paris. With this aim, we will analyze the concept of censorship in the Social Contract and the Rousseau's arguments in the works: Letters of the Mountain and the Letter to Christophe Beaumont, supported in the work of some experts on Rousseau's political work. Our studies allow us to conclude Jean-Jacques Rousseau does in fact, admit the possibility of censorship; however, the action of the censors must be restricted by public opinion, just like the prince's actions by the laws. In addition, if there is a similar process it should meet all the requirements of the civil law of the State where censorship takes place. Both in Paris and in Geneva Rousseau disagrees with the way they dealt with him and his works.
\end{abstract}

KEYWORDS: Censorship; Philosophy; Politics; Religion; Rousseau.

\footnotetext{
${ }^{1}$ Doutor em Filosofia pela Universidade de São Paulo (USP), São Paulo - SP. Brasil. Pós - doutorado em Filosofia pela Faculdade Jesuíta de Filosofia e Teologia (FAJE), Belo Horizonte - MG, Brasil. Professor de Filosofia da Universidade Federal de Uberlândia (UFU), Uberlândia - MG, Brasil.

${ }^{2}$ Mestra em Filosofia pela Universidade Federal de Uberlândia (UFU), Uberlândia - MG, Brasil. Professora da Universidade Estadual de Minas Gerais (UEMG), Belo Horizonte - MG, Brasil.

${ }^{3}$ Mestra em Filosofia pela Universidade Federal de Uberlândia (UFU), Uberlândia - MG, Brasil. Professora da Universidade Federal de Uberlândia (UFU), Uberlândia - MG, Brasil.
}

JÚNIOR, José Benedito de Almeida; TOMAZ, Loyana Christian de Lima; CASTRO, Luciana Xavier de. Rousseau e o paradoxo da censura. Griot : Revista de Filosofia, Amargosa-BA, v.18, n.2, p.176-186, dezembro, 2018. 


\section{Introdução}

Para nós, brasileiros, a palavra censura causa um incômodo profundo, pois temos memória de todos os males que o estabelecimento de departamentos de censura trouxeram para o desenvolvimento das nossas atividades culturais, artísticas e intelectuais, além da violência por meio da qual impuseram seus objetivos. Assim, ao lermos sobre este assunto em obras como as de Jean-Jacques Rousseau devemos tomar cuidado para não deixar com que nossa experiência cultural afete a interpretação conceitual e, até mesmo ao contrário, acreditamos que as ideias de Rousseau sobre este tema são bastante lúcidas, poderiam ser usadas para refletir sobre a nossa sociedade hoje e, por outro lado, não poderiam ser utilizadas para a defesa da censura nos moldes como conhecemos no século XX. Este filósofo defendeu a possibilidade da censura dentro de um contexto histórico que deve ser cuidadosamente analisado, muito diferente dos dias atuais em que governos a estabeleceram apenas para manter seu projeto de poder, sem nenhum interesse popular de fato.

Adentrando a questão conceitual na obra de Rousseau, poderíamos dizer que um leitor de sua obra poderia espantar-se com mais um de seus paradoxos, neste caso, o da censura. Como veremos adiante, o autor defende a possibilidade e, em alguns casos, até mesmo a necessidade, do estabelecimento de uma censura oficial, mas, questionou o fato de seus livros terem sido censurados na calvinista Genebra e na católica Paris. Ora, se ele defendia a possibilidade da censura, porque não aceitou simplesmente que seus livros fossem censurados? Tal paradoxo não deve ser estudado do ponto de vista apenas teórico, no caso dos processos de censura que sofreu há outras questões que deveriam ser levadas em conta e partem de um princípio mais básico da sociedade: o direito de defesa. Nas páginas seguintes, pretendemos apresentar a concepção de censura no Contrato Social e os argumentos com os quais Rousseau se defende da censura e das ordens de prisão aos quais foi submetido.

\section{A censura no Contrato Social}

A localização do capítulo Da censura no Contrato Social indica uma série de relações deste conceito com outros no pensamento de Rousseau e que pode nos elucidar seu sentido. O Livro IV apresenta uma série de instituições fundamentais para a organização do Estado como os sufrágios, eleições, tribunato, ditadura e a religião civil, portanto, ela não teria um papel pequeno ou irrelevante no contexto de sua obra política. Além disso, como veremos, a censura está relacionada com tópicos dos livros anteriores, em especial, as leis e a opinião pública:

\footnotetext{
Assim como a declaração da vontade geral se faz pela Lei, a declaração do julgamento público se faz pela censura. A opinião pública é a espécie de lei cujo ministro é o censor, que só faz aplicá-las aos casos particulares, a exemplo do príncipe. $O$ tribunal censório, longe pois de representar o árbitro da opinião do povo, não passa de seu declarador e, desde que disso se afasta, suas decisões tornam-se vãs e sem efeito. (ROUSSEAU, 1973, p. 141-142).
}

Há três paralelos estabelecidos por Rousseau, que necessitam ser esclarecidos para demonstração de sua concepção de censura. $O$ primeiro é entre a vontade geral e a opinião pública; o segundo entre a lei e a censura; o terceiro entre o ministro do tribunal censório e o príncipe. A respeito do primeiro paralelo podemos dizer que a vontade geral, para Rousseau é indestrutível e jamais pode estar errada, tal expressão normalmente é confundida com o 
conteúdo das leis, mas ela não se refere ao seu conteúdo e sim ao sentido próprio de se legislar. A vontade geral é sempre certa e tende à utilidade pública, mas nem sempre o julgamento dos que votam - seja o povo, sejam os representantes - possuem a mesma exatidão. Do mesmo modo, a opinião pública é sempre correta e tende ao bem geral, contudo, nem sempre o julgamento dos que definem o conteúdo da matéria possui a mesma exatidão deste sentido geral. Assim como a vontade geral é sempre certa, portanto, a opinião pública também é, no entanto, isto não se refere ao conteúdo mesmo que pode ter sido, sem dúvida alguma, fruto de enganos. Quanto ao segundo paralelo, podemos entender que a vontade geral não visa objetos particulares, assim o objeto das leis também serão gerais, como afirma Rousseau, a lei pode até estatuir privilégios e classes de cidadãos, mas não poderá nomear este ou aquele indivíduo para fruir destes privilégios ou pertencer a uma classe. Ora, a opinião pública também deve ser geral, isto é, poderá estabelecer, por exemplo, quais princípios morais podem ou não ser aceitos, quais ideias são boas ou não para a sociedade, mas não poderá nomear individualmente alguém como modelo ou como digno de censura. Concluindo este segundo paradoxo podemos dizer que a lei não pode nomear cidadãos, assim como a opinião pública também não pode fazê-lo.

$O$ terceiro paralelo, por sua vez, indica a relação entre o ministro do tribunal de censura e o príncipe, faz-se necessário esclarecer o que este conceito significa para Rousseau. No livro III, primeiro capítulo, Rousseau dedica-se a diferenciar o legislativo e o executivo ou, em última instância, o soberano e o Estado. Tal distinção é extremamente original na filosofia política, pois com ela resolve o antigo problema da submissão do povo aos seus chefes ou do estabelecimento de um contrato entre quem governa e quem é governado: para ele, não existe este contrato, quem governa o faz segundo a vontade de quem será governado, não será dotado de vontade própria. Em suas palavras:

Necessita, pois, a força pública de um agente próprio que a reúna e ponha em ação
segundo as diretrizes da vontade geral, que sirva à comunicação entre o Estado e o
soberano, que de qualquer modo determine na pessoa pública o que no homem faz
a união entre alma e corpo. Eis qual é, no Estado, a razão do Governo, confundida
erroneamente com o soberano, do qual não é senão ministro. Que será pois, o
Governo? É um corpo intermediário estabelecido entre os súditos e o soberano para
sua mútua correspondência, encarregado da execução das leis e da manutenção da
liberdade, tanto civil como política. Os membros desse corpo chamam-se
magistrados ou reis, isto é, governantes, e o corpo em seu todo recebe o nome de
príncipe. (1973, p. 80).

O príncipe, portanto, é corpo todo do governo, e este tem por função fazer com que as leis sejam cumpridas, portanto, devem aplicar a lei - que é sempre geral - em casos particulares. Por paralelismo entendemos, portanto, que o tribunal censório é encarregado de fazer com que a opinião pública seja sempre respeitada, porém, como ela é geral, este tribunal fica encarregado de aplica-la nos casos particulares. Assim como não cabe ao príncipe estabelecer as leis, não cabe ao tribunal definir o que é ou não a opinião pública, mas fazer com que sua vontade seja aplicada, repetindo as palavras de Rousseau: "O tribunal censório, longe pois de representar o árbitro da opinião do povo, não passa de seu declarador e, desde que disso se afasta, suas decisões tornam-se vãs e sem efeito." (1973, p. 142) Ora, assim como as leis devem servir de fundamento para o julgamento dos casos particulares, mas por mais precisas que sejam também precisam ser interpretadas, a opinião pública também precisa ser interpretada para que se julgue os casos particulares. É nesta zona enevoada da interpretação que se pode dar o equívoco tanto do príncipe, quanto do tribunal censório, pois há um limite muito estreito entre o que declara a opinião pública e a 
opinião particular dos componentes do tribunal censório. Contudo, tais limites são admitidos por Rousseau como próprios da natureza humana, por isso, Do contrato social não pode ser compreendida como uma obra que pretende apresentar formas de governo à prova de todo equívoco, não se trata de um programa de governo, mas de uma escala de medida da liberdade dos povos: "Antes de observar é preciso criar regras para as observações; é preciso uma escala para as medidas que tomamos. Nossos princípios de direito político são essa escala. Nossas medidas são as leis políticas de cada país". (1992, p. 553)

Até aqui, pudemos ver que a concepção de censura, presente no Contrato Social, é bastante lúcida no que se refere à possibilidade de equívoco do tribunal censório. Ainda que este, na opinião de Rousseau, possa ser estabelecido de modo legal os responsáveis por esta instituição social não estão isentos de erros. Há mesmo um kairós para a censura: "Concluise, daí, que a censura só pode ser útil para conservar os costumes, jamais para restabelecêlos. Estabelecei os censores durante o vigor das leis; desde que o percam, tudo estará perdido, pois nada de legítimo ainda terá força quando as leis já não a tiverem" (1973, p. 142). Rousseau considera que não é a natureza de um povo que determina seus usos e os costumes, mas sua opinião, isto é, os objetos de sua estima, aquilo que consideram belo. Uma sábia legislação deverá, por meio das leis, mudar estes objetos de estima, isto é, aquilo que o povo considera exemplar, o que formará sua opinião. Somente neste momento é que se pode estabelecer um tribunal censório para manter os costumes, mas as leis não têm força para restabelecer costumes quando estes tiverem perdido o vigor. Não cabe pois, ao tribunal censório, o direito de fazer leis, nem de declarar o que é a opinião pública. Conforme Nascimento: “A censura teria um papel importante quando o espírito do povo ainda estivesse em formação. A função principal desse tribunal seria a de administrar a opinião pública, que seria uma espécie de lei não escrita.' (1989, p. 52)

Nascimento observa que há diferentes perspectivas para compreender a opinião e da opinião pública em Rousseau. Em obras como $O$ discurso da desigualdade a busca pela estima pública parece ser negativa e estimulou as primeiras paixões violentas do ser humano. Em obras como o Emílio também há uma crítica à busca da aceitação da opinião. Contudo, na obra Considerações sobre o governo da Polônia a opinião pública assume uma tarefa fundamental no processo de educação no que se refere aos jogos públicos. Enfim, não se tratam de contradições de Rousseau, mas de compreendermos o sentido da expressão no contexto de cada obra. Quando se trata da censura na perspectiva que analisamos, nos referimos ao Contrato Social no qual Rousseau afirma:

\footnotetext{
A essas três espécies de leis, junta-se uma quarta, a mais importante de todas, que não se grava nem no mármore, nem no bronze, mas nos corações dos cidadãos; faz a verdadeira constituição do Estado; que todos os dias ganha novas forças; que quando as outras leis envelhecem ou se extinguem, as reanima ou as supre, conserva um povo no espírito de sua instituição e insensivelmente substitui a força da autoridade pela do hábito. Refiro-me aos usos e costumes e, sobretudo, à opinião essa parte desconhecida por nossos políticos, mas da qual depende o sucesso de todas as outras; parte de que se ocupa em segredo o grande Legislador, enquanto parece limitar-se a regulamentos particulares que não são senão o arco da abóbada, da qual os costumes, mais lentos para nascerem, formam por fim a chave indestrutível. (1973, p. 75).
}

A partir desta rede conceitual poderemos, agora, analisar os argumentos específicos de Rousseau, sobre o problema da censura nos dois casos específicos de Paris e Genebra. 


\section{O processo de Paris}

O Contrato Social foi publicado em maio e O Emílio junho de 1762, no mesmo mês de sua publicação o segundo livro e seu autor foram sentenciados: "Em 9 de junho o Parlamento de Paris condenou o Emílio e, ao mesmo tempo, decretou a prisão do seu autor, depois de a obra ter sido denunciada, dois dias antes, à Sorbonne; o livro foi queimado em 11 de junho" (ROUSSEAU, 2006, p. 44) Apesar de sua disposição de não fugir de seus perseguidores, os amigos de Rousseau insistiram que ele não se entregasse à justiça, pois o que o aguardava não era, com certeza, um processo justo. Rousseau continuou determinado em não, porém aceitou a insistência dos amigos por que, se permanecesse escondido, poderia colocar em risco as pessoas que ousadamente o acolheram mesmo em meio às mais severas perseguições.

A condenação em Paris não foi um processo de comum acordo entre as diversas posições que os próprios católicos franceses tinham a respeito das obras heréticas, inclusive as protestantes. Havia, conforme Lefevbre, conflitos de poder e jurisdição entre a poder temporal francês e o poder eclesiástico. Por outro lado, mesmo dentro da Igreja os conflitos eram bastante intensos, especialmente entre jansenistas e jesuítas. Independentemente destes conflitos, porém, $O$ Emílio conseguiu ser contestado e censurado por todos.

A produção bibliográfica atual sobre o caso Rousseau considera - e muito corretamente - que os processos contra ele poderiam até ser embasados pelas leis existentes na França, contudo, era justamente a crítica a esta situação que os filósofos iluministas estavam fazendo, isto é, o obscurantismo que pretendia reprimir e punir autores cujas obras contradissessem o que as autoridades eclesiais e políticas consideravam correto. Não havia, portanto, o direito ao contraditório nem em termos teóricos, nem em termos práticos e justamente por isso, um dos amigos de Rousseau advertiu-o sobre a publicação do Emílio. Em suas Confissões Rousseau relata que este amigo, ao ler o original do Emílio antes dele ser publicado e escreveu-lhe somente esta breve nota: "Eis um livro muito belo, mas do qual dentro em pouco se falará mais do que o autor desejaria." (1965, p. 574)

Lefevbre em sua obra Les pouvoirs de la parole (1992) observa que alguns argumentos da defesa que Rousseau faz de si mesmo por meio da Carta a Christophe Beaumont (2005) não são consistentes, do ponto de vista da ordem jurídica vigente. Para Lefevbre o fato de Rousseau ser protestante, estrangeiro e pelo fato de o livro ter sido publicado na Holanda, pois habitando Paris deveria submeter-se à justiça da França. Por outro lado, outro argumento que Lefebvre considera frágil, é que Rousseau insiste na necessidade de se separar o autor e a obra: considerar uma obra cheia de erros, não é motivo para condenar um autor, pois ele pode simplesmente estar errado ou vir a se retratar publicamente. Contudo, para Lefebvre, este argumento não é suficiente, pois $O$ Emílio não é apenas um livro teórico, porém, tem um evidente caráter autobiográfico:

\footnotetext{
Mas porque então falar constantemente sobre o autor e não se limitar a sua obra? Novamente, Rousseau levanta em novos termos, para a Igreja, o problema da condenação. A profissão de fé do vigário savoiano não é somente uma obra teórica, uma declaração de doutrina. É também uma história pessoal, é um homem envolvido em todo o seu debate com sua própria crença. Portanto, separar o homem de sua obra, o que Rousseau pediu ao arcebispo, porque acreditava ser possível, é realmente impossível. (LEFEBVRE, 1992, p. 76).
}

Independentemente deste aspecto, pois ele se resume a uma questão de debate literário - até onde uma obra é teórica e até onde é biográfica - Lefebvre concorda que a

JÚNIOR, José Benedito de Almeida; TOMAZ, Loyana Christian de Lima; CASTRO, Luciana Xavier de. Rousseau e o paradoxo da censura. Griot : Revista de Filosofia, Amargosa - BA, v.18, n.2, p.176-186, dezembro, 2018. 
condenação de Rousseau por parte do arcebispo não tinha cabimento. Para tanto, aponta duas razões que justificam esta posição:

Primeiro ele deixou a diocese de Paris e não estava mais sob a competência do arcebispo, limitado geograficamente. Segundo, ele é protestante. Ora a censura eclesiástica é uma pena espiritual que só pode alcançar aqueles que fruem dos bens espirituais que a condenação iria suprimir. (LEFEVBRE, 1992, p. 75).

Sobre o processo de Paris podemos dizer, com tranquilidade, que a ira dos censores políticos e eclesiásticos de Rousseau tinha razão de ser, uma vez que o Emílio é, de fato, uma crítica à política aristocrática e autoritária que dominava na França, tal como podemos constatar no resumo do Contrato Social que se encontra ao final do Emílio. Esta obra não é um ataque a todos os governos, mas serve muito bem como parâmetro para avaliar o grau de liberdade de um povo. Do ponto de vista religioso, a ira dos católicos tinha sua razão de ser, pois Rousseau o intertexto $A$ profissão de fé do vigário savoiano é uma crítica à hierarquia e ao ritual católicos, bem como Rousseau fará críticas também à possibilidade de uma educação catequética, motivo das mais inflamadas resposta de Christophe Beaumont. Sem dúvida, uma herança que recebemos deste conturbado período e da situação pela qual Rousseau passou foi a de que a censura sofrida por ele se encaixa naquele quadro que o próprio Rousseau havia descrito: quando os censores querem ser os árbitros da opinião pública, então ela está equivocada. A liberdade de pensamento e expressão teve neste caso um dos seus pontos mais marcantes na história ocidental.

\section{0 processo de Genebra}

Nas Cartas Escritas da Montanha (1764) Rousseau defende-se tanto do processo em Genebra, quanto das Cartas escritas do Campo (1763) publicadas anonimamente, cujo autor, revelado mais tarde, foi Jean Robert Tronchin, Procurador-Geral de Genebra e autor da condenação de Rousseau. Para redigir sua defesa, Rousseau reproduziu alguns trechos da condenação, os quais citamos abaixo:

\footnotetext{
"Meus livros são", dizem eles, "ímpios, escandalosos, temerários, cheios de blasfêmias e de calúnias contra a religião. Sob a aparência de dúvidas, o autor aí reuniu tudo que visa solapar, abalar e destruir os principais fundamentos da religião cristã revelada. Atacam todos os governos. Esses livros são tanto mais perigosos e repreensíveis quanto estão escritos no mais sedutor estilo de francês, quando aparecem sob o nome e a qualificação de um cidadão de Genebra e, segundo a intenção do autor, o Emílio deve servir de guia aos pais, às mães e aos preceptores. Ao julgar esses livros, não foi possível para o Conselho não lançar nenhum olhar sobre aquele que presumidamente é seu autor. (ROUSSEAU, 2006, p. $148-149)$.
}

Os argumentos apresentados para a condenação das obras e do autor parecem ter o mesmo sentido que Rousseau havia apresentado no capítulo sobre a censura, isto é, a intenção de manter os costumes de um povo. Neste ponto há duas hipóteses que podem ser levantadas para justificar a determinação do Procurador Geral em condenar rapidamente Rousseau, apresentaremos ambas de forma sucinta neste artigo: a questão do teatro e a situação política de Genebra.

Quanto à primeira questão trata-se do episódio da instalação de um teatro em Genebra. D'Alembert publicara, em 1757, o verbete da Enciclopédia intitulado Genebra que, dentre outros conteúdos, insistia nas vantagens - dentre elas econômicas - que haveria para 
esta cidade a instalação de um teatro e, cujos reflexos, seriam bons para toda a Europa, especialmente porque o rigor moral dos genebrinos serviria como exemplo para que se mudasse os costumes dos artistas de teatro da época, especialmente os da França. Rousseau logo percebeu que o verbete não era apenas teórico, mas estava envolto numa questão política: Voltaire, amigo do patriciado de Genebra tinha interesse em levar a cultura dos espetáculos de classe ou aristocráticos franceses o que, para Rousseau, seria um grande erro em relação aos costumes de Genebra.

Prado Júnior, em seu artigo $A$ retórica de Rousseau aborda o duplo aspecto desta carta de Rousseau a D'Alembert, por um lado, há uma interessante e original interpretação da relação entre o teatro e os costumes, a qual, apesar de muito interessante, não é nosso objeto neste artigo. $O$ outro aspecto é que não se pode esquecer que Rousseau também escreve esta carta porque o tema do teatro está envolto na questão política:

\begin{abstract}
Não basta, com efeito, mostrar como a Carta a D'Alembert opõe o caráter democrático e popular da festa ao caráter aristocrático do teatro francês, recolocando o texto em seu contexto genebrino e, em última instância, na dinâmica do conflito entre os Representantes e os Negativos. Tudo isso é certamente pertinente, e podemos retomar literalmente as proposições de M. Launay: "Jean-Jacques Rousseau punha-se como campeão do povo numa nova batalha, essencialmente política dessa vez, e venceu essa batalha: enquanto viveu, o teatro aristocrático não teve vez em Genebra." (2008, p. 302 $-303)$.
\end{abstract}

Será que a vitória política e social de Rousseau na questão do teatro repercutiu no episódio da censura? Entre a Carta a D'Alembert e as outras duas obras haviam se passado somente quatro anos. Os livros de Rousseau, portanto, apesar de seu caráter filosófico e, portanto, universal, não deixam de ser obras políticas também, que respondem às questões de seu tempo e se opõe à dominação política do patriciado. Numa carta de J.-L. Dupan a Freudenreich vemos a disposição do patriciado em relação a Rousseau, após o episódio do teatro em Genebra: "Seu maior prazer consiste em dizer: Genebra é a única cidade onde os comediantes não são recebidos, e fomos nós quem os impedimos. Rousseau escreveu contra os comediantes, é um nobre cavaleiro, ele pode dizer e escrever tudo, mesmo que seja contra a religião". (ROD, 1906, p. 18)

Quanto à questão da situação política de Genebra entra em jogo a divisão de classe dessa cidade, os censores atuaram contra uma obra que defendia princípios de um grupo político oposto ao seu:

O Embate entre as duas forças antagônicas - patriciado e burgueses - foram registradas por Rousseau em algumas de suas obras, tanto como elogio - como no Discurso sobre a origem da desigualdade entre os homens - quanto crítica - nas Cartas escritas da montanha. $\mathrm{O}$ embate dessas forças é o confronto entre a desigualdade e a igualdade, entre a liberdade enquanto a expressão da vontade soberana - porque é geral - e a ausência de vontade porque submetida ao arbítrio de outro. E esta discussão já está presente no Segundo Discurso, reaparece nas Cartas na análise feita por Rousseau das lutas políticas entre representantes e negativos. (2006, p. 40).

É importante destacarmos, de modo sintético a situação política de Genebra nesta última metade do século XVIII. Na introdução da edição brasileira das Cartas da Montanha, encontramos a descrição de Genebra e o conflito entre os burgueses e o patriciado. Rousseau pertencia à classe dos burgueses e Tronchin, bem como os outros membros do Pequeno Conselho, a do patriciado. Do ponto de vista jurídico o debate em torno do caso Rousseau se deu pelos que protestaram contra sua condenação, os 
representantes e os que defenderam a manutenção das sentenças os negativos, este direito autoriza a negar os recursos contra a prisão e a censura de Rousseau, sem possibilidade de se retomar o processo.

Alguns estudiosos observam que o processo não transcorreu inteiramente contrário à lei de Genebra. Édouard Rod apresenta argumentos cujo objetivo é demonstrar que o processo contra Rousseau poderia até ser considerado injusto, por não dar ao autor amplo direito de defesa, incluindo a liberdade física, no entanto, argumenta também que o processo não foi ilegal, que atendeu todas as exigências da normatividade jurídica de Genebra do século XVIII. No entanto, como veremos adiante, critica a fragilidade dos argumentos dos censores e dos juízes de Rousseau.

Uma das situações que denota a disposição do Pequeno Conselho e do Procurador Geral para condenar Rousseau foi a polêmica acerca do artigo 88 das Ordenações Eclesiásticas de Genebra. Marcet de Mezières, um dos amigos de Rousseau em Genebra, escreveu-lhe com o objetivo de afirmar ter encontrado a irregularidade que poderia anular a sentença contra ele. Trata-se do artigo 88 das Ordenações Eclesiásticas. Conforme Rod: "Marcet acrescentou um pós-escrito no qual afirma que ao folhear as Ordenações Eclesiásticas descobriu um artigo que estabeleceria a ilegalidade de ordem de prisão, ao menos no que concerne à religião." No artigo 88 lê-se:

Se houver alguém que dogmatize contra a doutrina estabelecida, e seja chamado para justificar: se ele se retrata, que se o tolere sem escândalo nem difamação; se ele perseverar, que seja admoestado várias vezes para tentar convencê-lo. Se, mesmo assim, considerar-se necessário utilizar uma severidade maior com ele, que seja interditado à Santa Ceia e que o magistrado seja avisado para que se assegure sua punição. (CALVIN, 1562, p. 67).

Na estrutura jurídico-política de Genebra, os casos de religião deveriam ser analisados primeiramente pelo Consistório e não diretamente pelo Conselho. Ora, mesmo com uma evidência tão forte de que o processo era irregular, o direito negativo permaneceu vitorioso sobre as representações e o processo não foi anulado. Le Rod observa que a resposta de Tronchin contra o direito de representação e que o conselho não poderia limitarse à interpretação do artigo 88 desta maneira o processo todo se enquadrara dentro da legitimidade:

Se o Consistório não age, sua inação amarraria o Conselho? Ou, pelo menos, ficaria ele reduzido à função de delator junto ao Consistório? Não foi isso que entendeu a Ordenação quando, depois de ter tratado do estabelecimento do dever e do poder do Consistório, concluiu que a potência civil permanece inteira, de sorte que ela não seja em nada derrogada em sua autoridade, nem tampouco no curso da justiça ordinária por nenhuma queixa eclesiástica. Essa Ordenação não supõe, pois, absolutamente, como se faz com as Representações, que nessa matéria os ministros do Evangelho sejam juízes mais naturais que os dos Conselhos. Tudo que é da alçada da autoridade em matéria de religião, é da alçada do governo. É o princípio dos protestantes e é, particularmente, o princípio de nossa Constituição, que, em caso de conflito, atribui aos Conselhos o direito de decidir sobre o dogma. (ROUSSEAU, 2006, p. 266-267).

Vemos que a argumentação de Tronchin denota, claramente, a intenção de não correr o risco de que o Consistório não condenasse Rousseau, por isso, impôs a interpretação de que os Conselhos não deveriam aguardar uma posição do Consistório para agirem, mesmo em caso de religião. Rod não discute este posicionamento do Procurador Geral, contudo, insistirá na fragilidade do argumento para definir a prisão de Rousseau, pois uma 
tal sentença como a da prisão de um autor deveria ter sido melhor fundamentada. Utilizando os arquivos originais - tanto os Extratos dos registros como as Notas - Rod observou que a fundamentação da legalidade da sentença era bastante frágil:

Quanto à questão da legalidade não encontrei nas notas senão duas linhas que em que ela poderia ter sido fundamentada: "Nós cremos que é passível de punição, e consequentemente, está decretada sua prisão." Estamos, pois, autorizados a entender que ela foi definida de modo imperfeito sumariamente." (ROD, 1906, p. $106)$.

Braillard, por sua vez, analisa a questão de modo progressivo e cuidadoso. Para ele, não há dúvida de que os ministros de Genebra acreditavam que estavam sendo fiéis ao juramento de fidelidade que todos genebrinos prestavam ao Evangelho; que esta sentença violava os direitos de um burguês de Genebra, Braillard diz não ter certeza, mas: "[...] o que eu sei bem, é que se eles não cometeram uma ilegalidade, cometeram uma falta contra a civilização, atentaram à equidade, ao direito de pensar, ao interesse do bem entender a religião que eles pretendiam defender. $(1879$, p. 203)"

Poderíamos nos perguntar, também, se o fato de ter havido amplo direito de defesa e garantia das liberdades individuais o processo ainda poderia ser considerado regular. Passemos, enfim, aos argumentos de Rousseau ao episódio de sua censura.

Em primeiro lugar, Rousseau admite a verdade de que pode ter cometido erros: "Sou homem e escrevo livros; então, também comete erros. Eu mesmo os percebo em grande número não duvido que outros vejam muitos mais e que existam ainda muitos que nem eu nem os outros, absolutamente, vemos." (2006, p. 151). A partir disso, argumenta que há uma grande diferença entre um livro que contem equívocos e um livro pernicioso, escrito com a intenção de ser nocivo. Assim, seria possível entender que Rousseau distingue o caso de um livro cujos erros são dolosos e outros livros em que os erros são culposos. Não se deve proceder de modo igual nestes casos, pois, conforme suas palavras: "Um homem não é culpado por prejudicar querendo servir" (2006, p. 152), mas pior do que isso é querer punir um autor por interpretações que se pode fazer do seu livro e que estejam em completo desacordo com o próprio autor amplia-se demais as possibilidades de censura e ninguém estaria livre dela, pois não se trata, neste caso, de punir o autor pelo que ele escreveu, mas pelo que se pode interpretar de suas palavras o que está completamente fora de seu alcance. Por fim, vejamos o primeiro argumento de Rousseau contra sua condenação em Genebra.

Isso, senhor, leva-nos de imediato ao estado da questão do qual, parece-me, o público se afasta. Se escrevi coisas repreensíveis, podem censurar-me por isso, podem proibir o livro. Mas, para difamá-lo, para me atacar pessoalmente, é necessário mais: a falta não é suficiente, é necessário um delito, um crime. Seria necessário que eu tivesse escrito com má intenção um livro pernicioso e que isso fosse provado, não como um autor prova que um outro autor se engana, mas como um acusador deve provar a culpa do acusado ante o juiz. (2006, p. 155).

O processo contra Rousseau, em Genebra, transcorreu como uma disputa literária, não somente do que ele havia escrito, mas também do que se poderia interpretar de seus escritos e isso não é argumento suficiente para se estabelecer um tribunal criminal: que o livro fosse censurado, isto poderia ser motivo de debates posteriores, mas considerar crime intencional, doloso, a elaboração e publicação destes livros, cujo objetivo seria solapar a ordem social de Genebra seria necessário reunir um conjunto de provas mais consistente do que a mera hermenêutica das palavras. No entanto, o caso de Rousseau em Genebra tem um outro agravante, que é destacado como segunda questão fundamental: “A segunda,

JÚNIOR, José Benedito de Almeida; TOMAZ, Loyana Christian de Lima; CASTRO, Luciana Xavier de. Rousseau e o paradoxo da censura. Griot : Revista de Filosofia, Amargosa - BA, v.18, n.2, p.176-186, dezembro, 2018. 
supondo-se o delito constatado, é fixar sua natureza, o lugar onde foi cometido, o tribunal que deve julgá-lo, a lei que o condena e a pena que deve puni-lo. Uma vez resolvidas essas duas questões, decidirão se fui tratado justamente ou não." (2006, p. 155). Uma das mais severas queixas de Rousseau, bem como dos seus amigos e parentes que tentaram por meio das representações retirar o aspecto criminoso das sentenças dada a ele em Genebra, é justamente de que ele foi julgado e condenado em um processo repleto de equívocos: a velocidade do processo, a condenação sem ouvir o autor - ele foi chamado à Genebra para responder as acusações já na condição de condenado, pois havia uma ordem de prisão contra ele mesmo antes de ter sido ouvido, quando poderia ter respondido o processo em liberdade.

\section{Conclusão}

Jean-Jacques Rousseau foi condenado em Paris e em Genebra por suas concepções religiosas e políticas. De certa forma, o ordenamento jurídico destes países autorizava este tipo de processo, desde que respeitados os trâmites normais, o que não se observou nos casos de Rousseau em nenhum dos casos. Ora, especialmente seus opositores de Genebra teriam certa razão em dizer que atacara os governos ou solapava a ordem social, de fato, seus livros questionavam o ordenamento político de Genebra em que os patrícios detinham poder sobre as outras classes sociais e era isto que não admitiam ser questionado, a ordem social que desejavam preservar era, especialmente, a do establishment genebrino. Quanto ao processo de Paris, Rousseau de fato atacara a decadente forma de poder monárquica, ancorada na censura, na repressão e no medo; assim como, as estruturas eclesiais da Igreja Católica que não condiziam com as origens do cristianismo. No entanto, o que se pode questionar é se o fato de um autor, por meio de seus livros, deveria ser punido da mesma forma que um criminoso comum, do ponto de vista de quem detém o poder, este seria o crime mais grave. Enfim, a coragem de Rousseau e de outros contemporâneos como Voltaire e Diderot - a despeito das divergências entre eles - legou ao ocidente uma sociedade na qual um autor pode até ser questionado pelo conteúdo de sua obra, mas dentro de garantias absolutas do seu direito de defesa. 


\section{Referências}

BRAILLARD, J. Les idées religieuses de J.-J. Rousseau. J.-J. Rousseau jugé par les genevois d'aujoud'hui. Genève. Jules Sandoz, 1879.

LEFEBVRE, Philippe. Les pouvoirs de la parole. L'Église et Rousseau. Paris: Editions du CERF, 1992.

CALVIN, Jean. Les ordonnances ecclésiastiques de l'église de Genève. Lyon : 1562. Disponível em http: // gallica.bnf.fr. Acesso em 13 de maio de 2008.

NASCIMENTO, Mílton Meira. Opinião Pública e Revolução. São Paulo: Nova Stella e EDUSP, 1989.

PRADO Jr., Bento. A retórica de Rousseau e outros ensaios. São Paulo: CosacNaify, 2008.

ROD, Édouard. L'affaire J. - J. Rousseau. Paris: Perrin et Cie. Librarie - Èditeurs, 1906.

ROUSSEAU, J. - J. Carta a Christophe de Beaumont e outros escritos sobre a religião e a moral. Tradução de José Oscar de Almeida Marques e outros. São Paulo: Estação Liberdade, 2005.

ROUSSEAU, J-J. Carta a D'Alembert. Trad. Roberto Leal Ferreira. Campinas. Editora da Unicamp. 1993.

ROUSSEAU, J. - J. Cartas Escritas da Montanha. Tradução de Maria C. P. Pissarra, Maria das Graças de Souza. São Paulo: EDUC; UNESP, 2006.

ROUSSEAU, Jean-Jacques. As confissões. Trad. Wilson Lousada. Rio de Janeiro: Ediouro, 1965.

Rousseau, J. - J. Do Contrato Social. Coleção Os Pensadores. Tradução de Lourdes Santos Machado. São Paulo: Abril Cultural, 1973.

ROUSSEAU, J. - J. Emílio ou da Educação. Tradução de Sérgio Milliet. Rio de Janeiro: Bertrand Brasil, 1992.

ROUSSEAU, J. - J. Oeuvres Complètes. Bibliothèque de la Plêiade. Paris: Gallimard, 1959 1995,5 volumes.

\footnotetext{
Contribuição dos autores

José Benedito de Almeida Júnior trabalhou com o problema da censura na obra teórica Contrato Social. Sob sua supervisão e colaboração, Luciana Xavier de Castro trabalhou o processo de Paris a partir da obra de circunstância Carta à Christophe de Beaumont e Loyana Christian de Lima Thomaz trabalhou o processo de Genebra a partir da obra de circunstância Cartas Escritas da Montanha. Todos os autores aprovaram a versão final do texto.
}

Autor(a) para correspondência: José Benedito de Almeida Júnior, Universidade Federal de Uberlândia, Instituto de Filosofia, Av. João Naves de Ávila, 2.121 - Bairro Santa Mônica, CEP 38408-100, Uberlândia MG, Brasil. jbeneditoalmeida@gmail.com 